\title{
Renta total agraria en la ciudad neoliberal. Recuperación de infraestructuras ferroviarias, expoliación de bienes comunes y urbanización en la Argentina sojera
}

Agrarian Total Income in the Neoliberal City. Recovery of Railway Infrastructures, Plundering of Public Properties and Urbanization in the Argentina of the Soybean

Renda agrária total na cidade neoliberal. Recuperação de infraestruturas ferroviárias, saqueio de bens comuns e urbanização na Argentina produtora de soja

María Alejandra Saus*

Recibido: 30 de junio de 2020

Aprobado: 23 de junio de 2021

https://doi.org/10.12804/revistas.urosario.edu.co/territorios/a.9259

Para citar este artículo

Saus, M. A. (2021). Renta total agraria en la ciudad neoliberal. Recuperación de infraestructuras ferroviarias, expoliación de bienes comunes y urbanización en la Argentina sojera. Territorios, (45), 215-237. https://doi.org/10.12804/revistas.urosario.edu.co/territorios/a.9259

* IHUCSO (UNL-CONICET). Correo electónico: produccioncientificaydocencia@gmail.com. ORCID: http://orcid. org/0000-0003-2112$710 X$ 
Palabras clave

Renta total agraria; ciudad neoliberal; infraestructura ferroviaria; extractivismo urbano.

Keywords

Agrarian total income; neoliberal city; railway infrastructure; urban extractivism.

Palavras-chave

Renda agricola total; cidade neoliberal; infraestrutura ferroviária; extrativismo urbano.

territarias 45

\section{RESUMEN}

Este artículo aborda la expansión económica debida a la exportación de commodities como un detonante de la expansión urbana en ciudades latinoamericanas. El objetivo es explicar esas dinámicas en aglomeraciones del área central de la Argentina, zona especialmente orientada al cultivo de soja en los últimos veinte años. No obstante, el énfasis está puesto en las secuelas urbanas de la recuperación de infraestructuras ferroviarias para la integración suramericana en el tráfico de cargas. Con un enfoque metodológico cualitativo, el artículo aporta una revisión bibliográfica y casuística, avanzando sobre problemáticas específicas de la ciudad neoliberal en el caso de Santa Fe. En la primera parte se abordan dimensiones macroeconómicas que inciden en la región, en la segunda se atienden las singularidades del plan ferroviario argentino y, por último, se explican los procesos de urbanización derivados de ambas.

\section{ABSTRACT}

The article addresses the economic expansion due to the export of commodities as a trigger for urban expansion in Latin American cities. The objective is to explain those dynamics in agglomerations of the central area of Argentina, a zone specially oriented to soybean cultivation in the last twenty years. However, the emphasis is placed on the urban consequences of the recovery of railway infrastructures for South American integration in freight traffic. With a qualitative methodological approach, the article provides a bibliographic and casuistic review, advancing on specific problems of the neoliberal city in the case of Santa Fe City. The first part addresses macroeconomic dimensions that affect the region, the second addresses the singularities of the Argentine railway plan and, finally, the urbanization processes derived from both are explained.

\section{RESUMO}

O artigo aborda a expansão econômica decorrente da exportação de commodities como gatilho para a expansão urbana nas cidades latino-americanas. O objetivo é explicar essas dinâmicas em aglomerações na área central da Argentina, uma área especialmente orientada para o cultivo de soja nos últimos vinte anos. No entanto, a ênfase é colocada nas consequências urbanas da recuperação da infraestrutura ferroviária para a integração sul-americana no tráfego de cargas. Com uma abordagem metodológica qualitativa, o artigo faz uma revisão bibliográfica e casuística, avançando sobre problemas específicos da cidade neoliberal, no caso de Santa Fé. A primeira parte aborda as dimensões macroeconômicas que afetam a região, a segunda aborda as singularidades do plano ferroviário argentino e, por fim, explicam-se os processos de urbanização derivados de ambos. 


\section{Introducción}

Este trabajo problematiza una serie de procesos económicos, políticos y territoriales que están emergiendo en el contexto suramericano, con el objetivo de estudiar su impacto a escala local urbana. Un conjunto de políticas públicas y de acciones privadas han impulsado medidas de recuperación de infraestructuras de transportes que, siendo motivadas por dinámicas macroeconómicas e ideadas por organismos nacionales y supranacionales de planificación, repercuten a nivel local de un modo que desafía las indagaciones de corte municipal. Nuestra interpretación de esas dinámicas, especialmente las asociadas a la modernización de los ferrocarriles mercantes, sugiere la existencia de flujos de materias primas y de capitales de origen financiero - extraídos de e invertidos en la región- persistiendo esta zona en un papel periférico en la geografía económica del sur global. En ese universo quedan implicadas: la exportación mayoritaria de commodities hacia los países asiáticos y la importación de tecnología ferroviaria producida por China y empleada en la construcción de infraestructuras.

Partiendo de argumentar que, entre esas dinámicas de acumulación capitalista, cuya índole es territorial, se ciernen estrategias de un nuevo tipo de imperialismo, vamos a interpretar esos procesos a partir del concepto de acumulación por desposesión (Harvey, 2004). El autor cuestiona la acumulación originaria como atributo de la etapa inicial del capitalismo, arguyendo que esta participa de una dinámica que debe ser repetida cíclicamente, a fin de motorizar la acumulación. Por su parte, y con respecto a la ciudad, Viale (2017) asevera que la especulación inmobiliaria es la faz urbana de la acumulación por desposesión y que los inmuebles serían commodities, del mismo modo que las oleaginosas lo son para el ejemplo de la agricultura argentina. Sin embargo, en este artículo vamos a cuestionar ese argumento binario para sostener, en cambio, que las lógicas de ambos medios - el rural y el urbano - están interrelacionadas y atravesadas por dinámicas multiescalares, que impregnan el territorio nacional y las políticas públicas impulsadas por los estados en sus respectivos niveles.

Aquí indagamos la noción de escala soslayando su dimensión cartográfica, para convertirla en una herramienta y una construcción social que relaciona lo global, nacional, regional y local. Buscamos superar estériles compartimentaciones y situar en el centro del análisis la imbricación mutua de todas las escalas. Por tal razón, a los modelos analíticos tradicionales - que asumen las escalas estatales como "muñecas rusas"- hemos incorporado las coyunturas, los sujetos, las políticas públicas y las formas de penetración del capital global como acciones no sistemáticas que desafían la gobernanza regional/local. Enfatizamos, entonces, las interrelaciones dinámicas territarias 45 217 
entre actores socio-económicos e institucionales de distintas escalas para valorar la implicación del Estado y del capital en las configuraciones territoriales de las infraestructuras ferroviarias, al concebir las escalas espaciales como constructos sociales de particulares configuraciones en constante mutación (Brenner, 2003; Swyngedouw, 2004).

Presentado el panorama general, lo que impulsa esta reflexión en el campo de la teoría urbana es que algunas aglomeraciones latinoamericanas están siendo convertidas en receptoras de las inversiones extranjeras en infraestructuras de transporte $y$, también, en destinatarias de las rentas del sector agrícola nacional. Entendemos por renta total agraria al excedente generado en dicha producción que corresponde a la renta de la tierra o renta agraria y al retorno del capital invertido. Si bien la primera es apropiada por los terratenientes y la segunda por los capitalistas agrarios, en el modelo argentino los dueños de la tierra pueden o no coincidir con los productores. Entonces, la renta total de la actividad está conformada por ambas: la renta agraria y la renta media del capital (Palmieri \& Noguera, 2015), y se ha decidido no desarrollar un estudio de la composición interna del sector, por no ser ese el eje principal de este trabajo. Además, argumentamos que esas prácticas productivas indirectamente profundizan desigualdades socio-espaciales en los procesos de urbanización. Actualmente, la construcción de infraestructuras, la expoliación de bienes comunes en operaciones inmobiliarias pergeñadas sobre el patrimonio ferroviario y la expansión de la urbanización (en vertical y en horizontal) son modalidades destinadas a absorber los excedentes de otros sectores económicos. Esas acciones crean nuevas formas de extractivismo inmobiliario, entendido este como nicho de reproducción, acumulación y sobreacumulación del capitalismo en la ciudad neoliberal (Hidalgo et al., 2016).

A fin de desarrollar esta propuesta interpretativa de las dinámicas macroeconómicas que repercuten en las ciudades latinoamericanas - en general-y en la Argentina - en particular-, adoptamos un enfoque metodológico cualitativo, nutrido de una revisión bibliográfica, casuística y periodística tendiente a ofrecer un artículo de reflexión sobre las problemáticas enunciadas. El trabajo se compone de tres partes que están íntimamente relacionadas, pero que decidimos separar debido a los campos disciplinares específicamente implicados en cada una de ellas. En la primera sección desarrollamos algunos lineamientos macroeconómicos y geopolíticos conducentes a explicar aspectos propios de las escalas global y regional. En el segundo apartado ponemos el acento en el territorio argentino y en los roles ferroviarios asumidos por la ciudad de Santa Fe, en el contexto explicado en la primera sección. La tercera parte está concentrada en la escala urbana, donde tienen lugar micro 
procesos de urbanización que también son ejemplificados por otras ciudades del área central de la Argentina como Rosario y Buenos Aires. En las reflexiones finales recapitulamos las articulaciones de dichas partes para abrir una discusión sobre las transformaciones aludidas.

\section{Reprimarización en Suramérica: estrategias globales y aperturas regionales}

Retomamos el concepto de acumulación por desposesión para profundizar en su complejidad y, también, esclarecer las modalidades que adquiere el capitalismo contemporáneo. Harvey (2004) argumenta que la principal característica del nuevo imperialismo es su creciente intento de acumular por medio de la desposesión, predominando esa tendencia por sobre la reproducción ampliada de los patrones de acumulación centrados en la industria. Asimismo, explica que los excedentes de la producción capitalista pueden absorberse por medio de tres canales: inversiones a largo plazo - como las dirigidas a construir infraestructuras-, desplazamientos espaciales o una combinación de ambas modalidades.

En la primera vía median las instituciones financieras y/o estatales que amortizan sus gastos si las inversiones muestran ser productivas. De lo contrario, podría haber devaluaciones de esos activos o una crisis fiscal. En cuanto a los desplazamientos espaciales, la interpretación del autor involucra un ejercicio de historia de larga duración. Harvey explica que, en el siglo XIX europeo en lugar de enfrentarse los problemas de sobreacumulación y los conflictos de clase en un marco de justicia social, se avanzó hacia el imperialismo para poder resolverlos, creando así nuevos monopolios e injusticias en otros territorios del planeta. En el siguiente ciclo, a mediados del siglo $\mathrm{xx}$, el desarrollismo impulsó alianzas entre países centrales para sostener la acumulación del capital productivo que tenía a Estados Unidos como potencia líder. Tras la crisis de la década de 1970, las grandes instituciones del capital financiero se convirtieron en las abanderadas de la desposesión. Por esas etapas, Harvey sostiene que la acumulación es un proceso tendiente a ser reiterado y que asume renovadas apariencias.

Siguiendo los ciclos hegemónicos de Arrighi (1999) y considerando la expansión del capital financiero como anuncio de una nueva crisis y la antesala de otra hegemonía nacional del capital productivo, resulta difícil imaginar que Estados Unidos - aunque actualmente posea un liderazgo disputado - vaya a aceptar pacíficamente la transición hacia la que podría ser una hegemonía asiática. Entonces, aún habría un predominio estadounidense en torno al control del capital financiero, económico, tecnológico y militar; mientras China despuntaría como potencia enfocada en la expansión del capital productivo en América Latina, con modalidades semejantes a las que había territarios 45 219 
desplegado Estados Unidos (Bolinaga \& Slipak, 2015). Otros autores visualizan con mayor protagonismo el desempeño de aquel país, afirmando que: "China comienza a devenir de taller manufacturero del mundo a centro tecnológico con capacidad de competir con el Norte global y sus centros posfordistas" (Merino \& Adriani, 2019, p. 4).

Inspirados en la teoría del ciclo económico de Kondratieff y en las hegemonías ideadas por Arrighi, también podríamos reconocer etapas urbanísticas vinculadas a las innovaciones tecnológicas en infraestructuras de transportes y a los paradigmas tecno productivos (Pérez, 2010). Estas etapas se inician en el siglo XIX con la preeminencia ferroviaria británica y su estímulo a la urbanización, transitando luego hacia el relevo norteamericano con la supremacía del modo automotor, la construcción de autopistas y los modelos de suburbanización (Rodrigue, 2013). Ubicada en esa perspectiva histórica, la reciente recuperación de los ferrocarriles de cargas en Suramérica estaría asociada a China y a su estrategia geopolítica de difusión tecnológica, con secuelas aún inciertas para las ciudades (Rivera et al., 2018).

Es aquí donde nuestra región queda problemáticamente situada en el mapa mundial y subordinada a un modelo extractivo del cual la economía asiática obtiene sus materias primas, al tiempo que ubica sus excedentes de producción a través de inversiones ferroviarias y por medio de la provisión de material rodante. Dado que las recientes iniciativas de los estados suramericanos, calificadas como "neodesarrollistas" no han modificado el patrón de acumulación preexistente (Katz, 2015; Fernández, 2016), la situación macroeconómica parece confirmar la inercia de los sectores dominantes de nuestros países para acompañar estrategias de industrialización, y el territorio ratifica sus esquemas históricos de exportación primaria.

Eso conlleva al neoextractivismo y a la reprimarización de las prácticas económicas en la actual fase de acumulación capitalista, vinculada a la expansión de China, que pretende erigirse en un nuevo centro (Barzola \& Baroni, 2018). Si bien durante la primera década del 2000 las exportaciones a ese país permitieron una buena tasa de crecimiento en la Argentina y en la región en general, el aumento reciente de las exportaciones - en el mapa de un regionalismo abierto - ha debilitado los intercambios comerciales entre los estados suramericanos y no permite seguir incrementando sustancialmente el PIB. Según Merino y Adriani (2019), China absorbe el $40 \%$ de las materias primas exportadas y por cada punto de incremento de su PIB se estima un arrastre de un $0,4 \%$ del latinoamericano. Además, siguiendo el argumento de dichos autores, nuestros países presentan una inserción limitada en las cadenas globales de valor y lo hacen en los eslabones de menor valor agregado ajenos a los núcleos innovativos. 
Por otra parte, el patrón de especialización destinado al mercado externo está dominado por empresas transnacionales y concentrado en pocos productos, dependientes de paquetes tecnológicos como la soja transgénica y los agroquímicos. Además, dichos paquetes consolidan un régimen de propiedad intelectual, patentes, licencias y monopolios corporativos dominados por los países centrales (Harvey, 2014). En cuanto a las políticas públicas y a los mecanismos de regulación, las disputas entre un regionalismo autónomo (que cuestiona el papel de la periferia en el orden global y procura estrategias de desarrollo endógeno) y un regionalismo abierto (que no lo cuestiona e intenta adaptarse al capitalismo mundial) parecen estar resolviéndose hacia el segundo modelo de posicionamiento regional.

De hecho, el plan de recuperación del Ferrocarril Belgrano Cargas en la Argentina - que tiene a China como principal fuente de financiamiento- replica varios de los proyectos de infraestructura previstos en el Eje Capricornio de la Iniciativa para la Integración de la Infraestructura Regional Suramericana (IIRSA), impulsada por Brasil en el año 2000, y el Consejo Suramericano de Infraestructura y Planeamiento (COSIPLAN) creado en $2009 .{ }^{1}$ Este no ha tendido a revertir aquel enfoque de apertura destinado a la demanda externa y eso puede verificarse en la extracción del cobre chileno, el carbón de Colombia o el cultivo de soja en la Argentina, que es el tercer exportador luego de Estados Unidos y Brasil.

Los países pertenecientes a la Cuenca del Paraná conforman el mayor aglomerado de producción de soja a nivel mundial desde hace más de una década y han incrementado sustancialmente la superficie sembrada con ese cultivo: Brasil 70\%, Argentina $120 \%$, Paraguay $125 \%$ y Bolivia $60 \%$ (Aceval \& Álvarez, 2018). El tráfico de esas mercancías está vinculado a la Hidrovía Paraguay-Paraná, que también está contemplada en la cartera de proyectos de IIRSA, al igual que la concreción de obras de infraestructura vial para fortalecer y desarrollar un corredor interoceánico hacia puertos chilenos del Pacífico.

En la Argentina se exporta más del $95 \%$ de la producción de soja, especialmente a China, y ha habido un aumento del 196, 9\% de la superficie sembrada con esa oleaginosa entre los años 1996 y 2014. En 2011 implicaba el $25 \%$ de las exportaciones totales de un país que ha expandido su frontera agrícola hacia el norte del territorio nacional. Discriminado por provincias - y de norte a sur- ese aumento del área cultivada registra los siguientes guarismos: Formosa $1.400 \%$, Chaco 512, 8\%, Santa Fe 37, 3\%, Córdoba $212,6 \%$, Entre Ríos 569, 4\% y Buenos Aires 359, 8\% (Gómez Lende, 2015). Por otra parte, la organización productiva está conformada por pools de siembra entre los que destacan: conglomerados de bancos
${ }^{1}$ Información de IIRSA en www.iirsa.org

tersitarios 45 221 
2 Información del Ministerio de Transporte en https://www.argentina. gob.ar/transporte/trenesargentinos-infraestructura

\section{tersitarias 45}

extranjeros, agroindustrias y productores, pools regionales y grandes grupos económicos nacionales y extranjeros. El Estado nacional se apropia parcialmente de esa renta, a través de retenciones que han implicado serias resistencias y conflictos entre gobierno y terratenientes.

Transcurridos largos años de abandono, los ferrocarriles argentinos impulsados por IIRSA, COSIPLAN y el Ministerio de Transporte de la Nación procuran dinamizar el tráfico exportador de esos commodities que motivan el interés asiático. ${ }^{2}$ En el caso de la Argentina, el flujo extractivo retorna convertido en financiamiento y tecnología ferroviaria que China provee, justamente, para movilizar la producción de las materias primas que pretende extraer. De hecho, en 2010 se firmó un convenio entre la entonces Secretaría de Transporte de la Nación y la empresa constructora China Machinery and Engineering Corporation (CMEC) con el objetivo de recuperar $1.600 \mathrm{~km}$ de vías del Ferrocarril Belgrano Cargas. Esa iniciativa permitiría mejorar las conexiones entre las provincias de Salta, Chaco y Santa Fe para elevar las toneladas transportadas hacia los puertos de la Región Metropolitana de Rosario (Schweitzer, 2014). Discursivamente, el plan fue promovido como medio para mejorar las economías regionales, cuestión que resulta engañosa dado que carece de líneas transversales y solo se recuperan las trazas de la red ferroviaria decimonónica (figura 1).
Lo notable para nuestros intereses disciplinares radica en que la modernización ferroviaria trae al dorso — además de profundos desequilibrios territoriales (Rascovan, 2016) - el desmantelamiento de infraestructuras obsoletas en áreas centrales urbanas, al implicar aquella el trazado de variantes y nuevas líneas para largas formaciones de trenes mercantes que ya no podrían atravesar las ciudades. Dicha realidad impulsa las apetencias del mercado inmobiliario, allí donde las infraestructuras en desuso persisten abandonadas, alentando así proyectos sectoriales de renovación urbana en esos "vacíos urbanos" que guardan una conexión con el pasado, pero sin poder establecer una nueva en el presente (Etulain, 2008).

\section{Recuperación de ferrocarriles mercantes: obras y expoliaciones}

La modernización del Ferrocarril Belgrano busca mejorar la eficiencia del tráfico de cargas y ello no solo incluye renovar infraestructuras para aumentar las velocidades y la cantidad de vagones remolcados, también implica desviar su paso de la trama urbana de la ciudad de Santa Fe, donde actualmente los trenes deben disminuir su velocidad para evitar accidentes y descarrilamientos. Por ello, desde el Estado nacional comenzaron a idearse alternativas para resolver ese cruce a nivel. Los estudios técnicos implicaron dos etapas con distinto signo político, pero ambas con idéntico horizonte tendiente 
Figura 1. Etapas de la obra de recuperación del Ferrocarril Belgrano Cargas

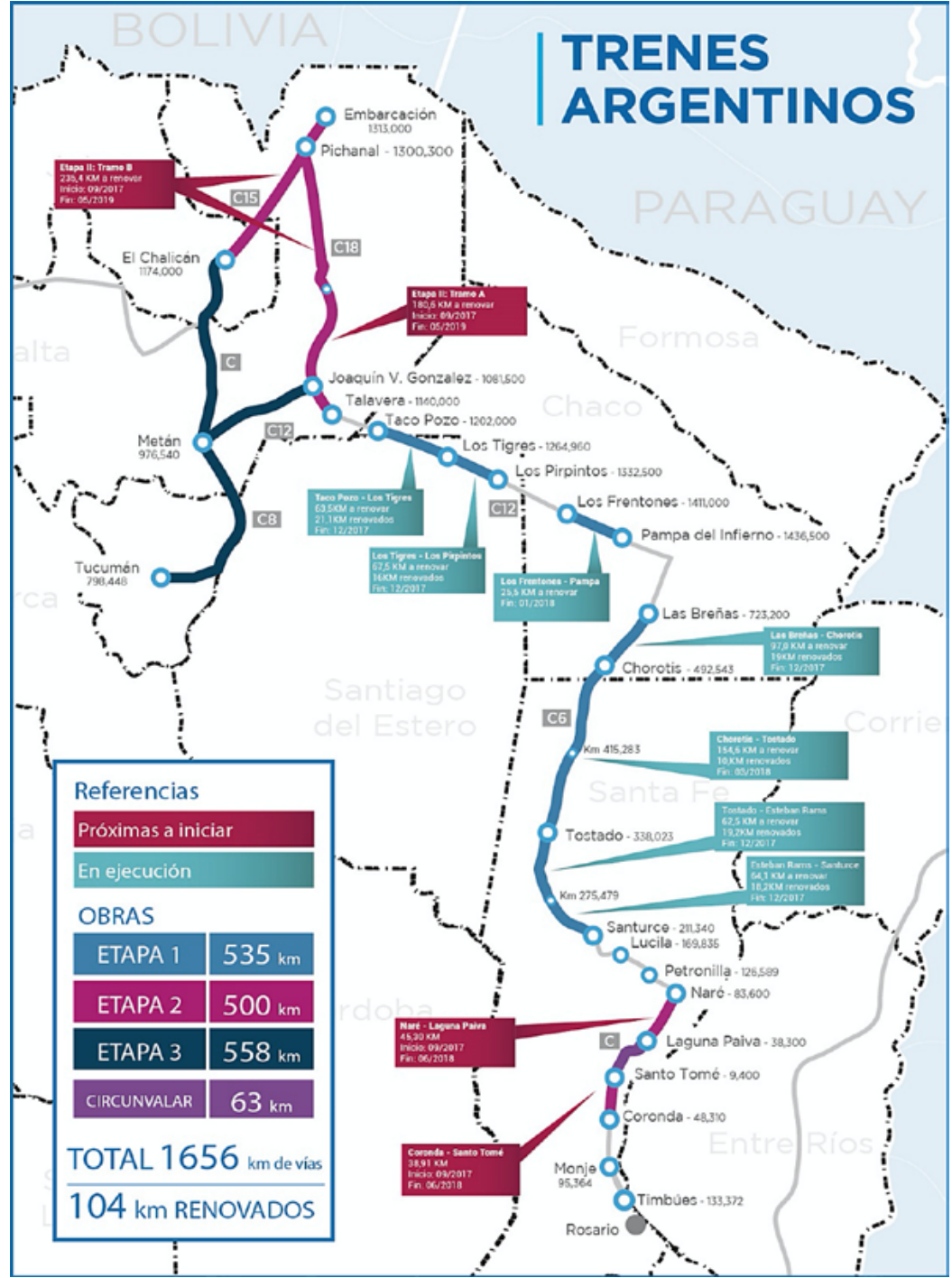

Fuente: tomado del artículo ("Renovaron más de 200 km”, 2017), publicado en el sitio oficial www.argentina.gob.ar

a recuperar los ferrocarriles para impulsar una economía primaria y con el mismo organismo supranacional de financiamiento.
El primer antecedente se remonta al año 2010 cuando la Corporación Andina de Fomento (CAF) aprobó un préstamo 
3 Licitación Pública Internacional LP 16ADIF-2016. https://www. argentina.gob.ar/transporte/trenes-argentinosinfraestructura territarias 45 destinado al Proyecto de Recuperación y Mejoramiento del Ferrocarril General Belgrano ("CAF otorga...", 2010), momento en que Transporte era una Secretaría del Ministerio de Planificación Federal, Inversión Pública y Servicios. El propósito era elaborar un anteproyecto para la Circulación Ferroviaria en la Ciudad de Santa Fe. Se proyectaba un movimiento de tres millones de toneladas para el horizonte 2030 , en trenes de ochenta vagones, con picos de veinte formaciones diarias de $2 \mathrm{~km}$ de largo, cuestión imposible de imaginar en medio del tráfico vehicular urbano. Por lo tanto, se estudió una traza existente en alto nivel y se propusieron dos variantes a nivel, pero hacia el oeste del ejido urbano.

El siguiente paso fue dado en el 2016 y la iniciativa provino de Trenes Argentinos Infraestructura, perteneciente al ahora subido de rango Ministerio de Transporte de la Nación. Entre los tramos licitados se hallaba el Pliego de Bases y Condiciones Generales para la Contratación de Servicios de Consultoría para el Análisis Económico y Proyecto Ejecutivo para la Circunvalación Ferroviaria de la Ciudad de Santa Fe (figura 2). ${ }^{3}$ En esta segunda etapa la opción de circular por la trama urbana quedaba completamente descartada, haciendo el pliego explícita mención

Figura 2. Circunvalación ferroviaria
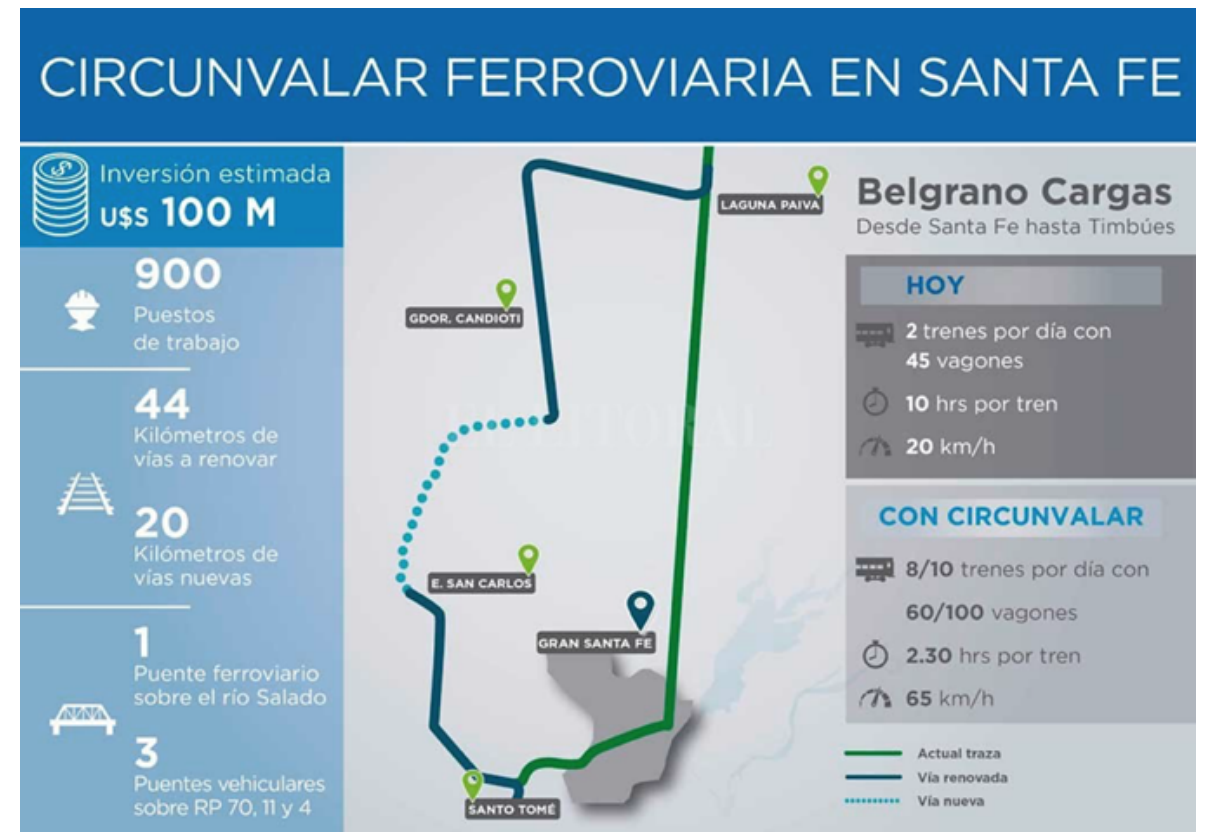

Fuente: tomado del diario El Litoral ("Circunvalar Santa Fe", 2019). 
a la circunvalación, cuyos estudios de consultoría también fueron financiados por la CAF. Actualmente, el plan de expropiaciones a cargo de la Provincia está en marcha en el Gran Santa Fe (GSF) y se estima que las obras culminarían en el año 2023 (Castaños, 2018).

En este punto, de un tema de integración regional destinado a la exportación de materias primas comenzamos a aproximarnos a las problemáticas urbanas en la ciudad neoliberal. Habíamos dicho, siguiendo a Hidalgo et al. (2016), que la construcción de infraestructuras de transporte, la expoliación de bienes comunes y la expansión de la urbanización eran tres modos de extractivismo. Si bien ese concepto proviene de la actividad minera y de la extracción de recursos naturales a escala territorial y a cielo abierto, ha sido adaptado al medio urbano para explicar procesos equivalentes. Por tales razones, fue reemplazado el concepto de recursos naturales por el de bienes comunes, representados en este artículo por el espacio ferroviario desafectado, patrimonio estatal, que podría consumirse con fines privados.

Nos referimos a la posible expoliación debida a la clausura del espacio por donde actualmente corre el Ferrocarril Belgrano en el tejido urbano, lo que convierte a ese dominio público en patrimonio ferroviario $\mathrm{y}$, por lo tanto, en un bien comercializable como cualquier otra propiedad en el mercado inmobiliario. Esto es así porque la rentabilización del espacio ferroviario depende del artificio jurídico de la desafectación, ya que los bienes de dominio público afectados a un servicio no pueden intervenirse ni venderse cuando están operativos (Madrigal Tascón, 1988). En la Argentina, al ser desafectados salen de la órbita de la Administración de Infraestructuras Ferroviarias (ADIF), se convierten en bienes patrimoniales del Estado y son enajenables, embargables, expropiables o pueden ser comercializados como cualquier otro bien por la Agencia de Administración de Bienes del Estado (AABE) ("Nuevo desarrollo urbanístico...", 2018).

Empero, que sea resguardado el uso público - que motivara las expropiaciones para instalar infraestructuras en el siglo XIX- debiera ser hoy el principal objetivo municipal para resolver el destino de las estaciones y trazas desafectadas, sobre todo cuando se trata de una ciudad intermedia que debe aspirar a una movilidad urbana sostenible y ya ha consumido gran parte de su espacio ejidal. Puntualmente, en el caso de Santa Fe, eso ocurriría con el cuadro céntrico de 24 has de la ex estación del Ferrocarril Belgrano (figura 3), para el cual existe un proyecto municipal de urbanización con apertura de calles transversales y construcción de torres. ${ }^{4}$ Dicho proyecto, además de consumir el espacio público abierto, dejaría al antiguo edificio de pasajeros desarticulado de los demás componentes del patrimonio industrial (figura 4). En relación al destino de las trazas ferroviarias desafectadas, el panorama local es más incierto aún y preocupa
${ }^{4}$ Si bien la estación de pasajeros está clausurada desde la década de 1990, la consagración de su inutilidad futura $y$ el traslado de las actuales maniobras cargueras ban disparado el proyecto urbano. 
Figura 3. Cuadro de la estación Belgrano

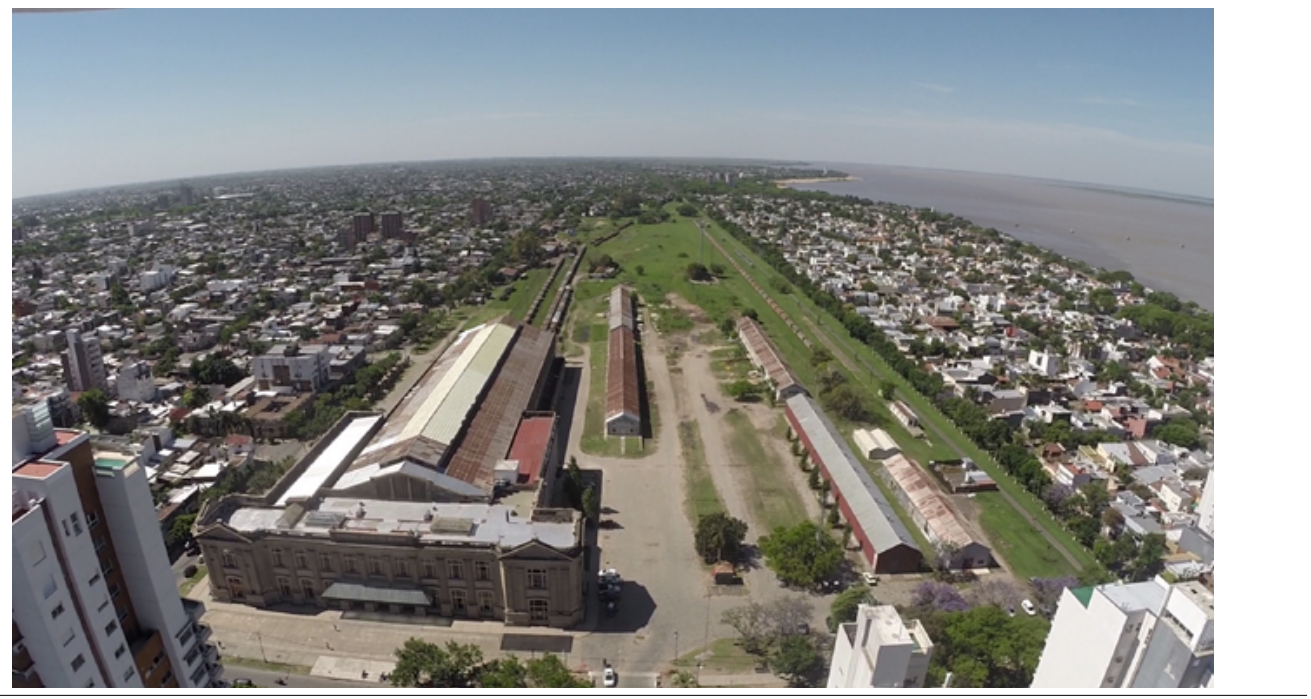

Fuente: tomado de \#Encuentro Santa Fe (“sobre el posible desarrollo”, 2018).

Figura 4. Proyecto de urbanización para el cuadro de estación

territarias 45

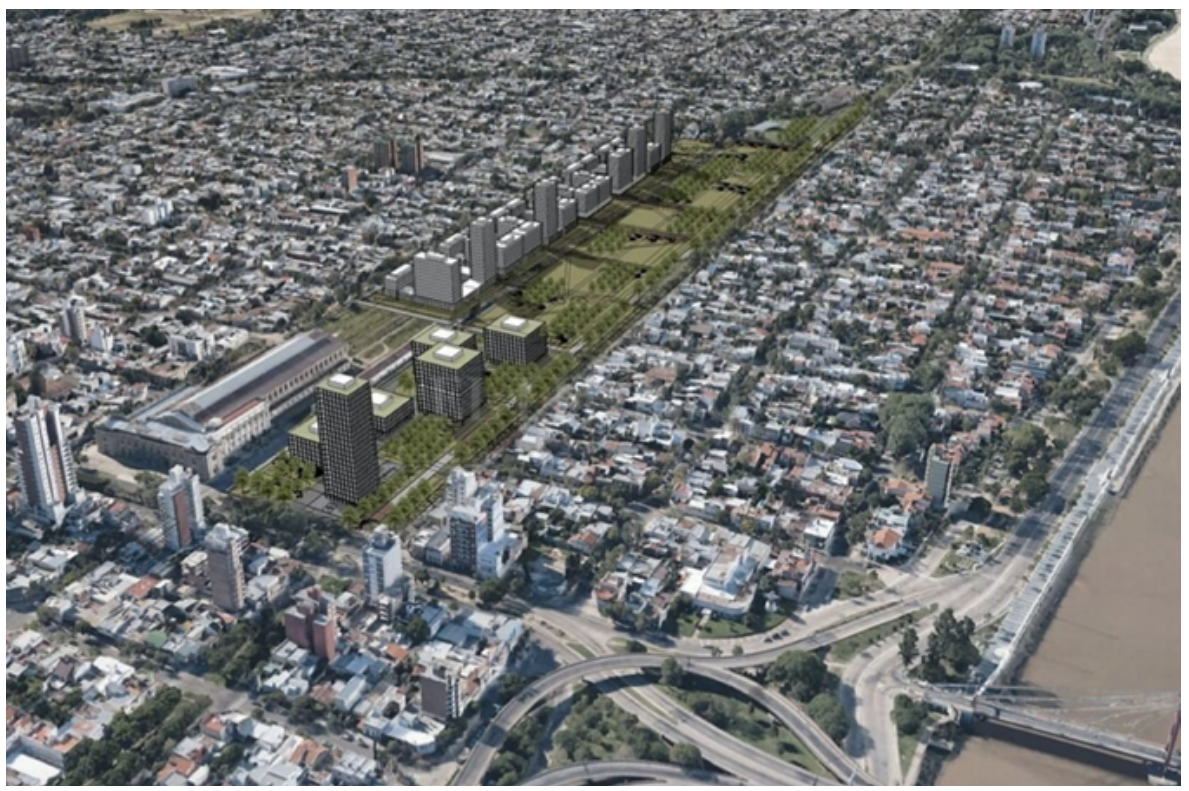

Fuente: tomado del diario El Litoral (Pereira, 2020). 
el posible consumo inmobiliario de esos espacios que tienen tanto potencial.

En torno a los desarrollos inmobiliarios, los actores políticos establecen alianzas con los promotores y suelen ceder ante sus presiones. Entonces, la planificación urbana y territorial queda subordinada a intereses sectoriales en lugar de mejorar ese bien común que es la ciudad y de cuyos beneficios se apropian los desarrolladores privados. Esta situación contribuye al extractivismo inmobiliario, produciendo la expoliación de ciudadanos y de bienes comunes que ya hemos mencionado además de la esquilmación del medio natural (Hidalgo et al., 2016). Asimismo, no se trata de acciones aisladas, sino de prácticas cuyas rentas, ganancias y actores sociales están relacionados haciendo converger sus intereses particulares.

Tras la crisis productiva global y los ensayos neoliberales de la década de 1970, el capital debía buscar nuevos nichos de reproducción-acumulación-sobreacumulación. Así encontró en el sector inmobiliario un terreno fértil para expandirse aprovechando las inyecciones del capital financiero. Este sector está en la base de la ocupación extendida de la urbanización y, además, en los cimientos de las estructuras de alta compacidad que inundan las áreas centrales de la ciudad neoliberal. Es en este tipo de ciudades donde echa raíces el neoliberalismo, con las peculiaridades propias de cada trayectoria nacional, pero articulado translocalmente.
Otro concepto que la ciudad de Santa Fe bien puede ejemplificar es la noción de destrucción creativa (Theodore et al., 2009). Esto ocurre porque, mientras algunos predios ferroviarios como el cuadro de la ex estación del Ferrocarril Mitre están abandonados en el suroeste de la ciudad con mejoras iniciadas recién en 2021 tras años de abandono, todas las energías del Estado municipal fueron puestas en la recuperación del ya mencionado edificio de viajeros de la ex estación del Ferrocarril Belgrano que fue remozada hace una década. Además, otros recursos fueron orientados a la puesta en valor del Blvr. Gálvez donde ese edificio está emplazado, de modo que las obras públicas operan con la misma selectividad que lo hace el mercado, en lugar de procurar matizar esas lógicas excluyentes y segregativas.

Especial atención merece la reciente subasta de terrenos del ex Ferrocarril Santa Fe en zona céntrica y por parte de la AABE. Aquí el Estado nacional había intentado recuperar unos cinco millones de dólares de los 117 que costaría la circunvalación ("Nación quiere financiar...”, 2018). Pero, además de la grotesca distancia entre ambas cifras y de la presunción que solo irá a cubrir gastos fiscales corrientes, los conflictos locales han quedado expuestos en las reuniones de vecinos. En ellas, los equipos técnicos de los concejales opositores hicieron estimaciones con otros números sobre el volumen de la operación inmobiliaria, las 
condiciones de edificabilidad del sector y el marco jurídico requerido para que lo recaudado pueda retornar a la ciudad de Santa Fe ("Terrenos de Candioti Sur...", 2018).

En suma, los procesos de urbanización están absorbiendo los excedentes producidos a escala global, regional, nacional y local, y en ello coinciden las acciones y los actores del capitalismo y del Estado en perspectiva multiescalar. Por ejemplo: las ciudades latinoamericanas están incorporando los excedentes chinos convertidos en infraestructuras de transporte a escala regional, están creando programas estatales de vivienda social que esos capitales financian a nivel nacional y están generando rentas agrarias reinvertidas en unidades edificadas. La gobernanza urbana y la planificación territorial evidencian así su incapacidad de gestionar esos procesos, mientras la flexibilización de los instrumentos que regulan el uso del suelo aumenta los beneficios inmobiliarios, incrementando los precios de las propiedades hasta cifras irrisorias con respecto a las posibilidades de un salario mínimo.

\section{Commodities rurales y urbanos: ciudades impulsadas por el campo}

El tercer ítem que señala Hidalgo et al. (2016) como modalidad para absorber excedentes es la expansión de la urbaniza-

\section{territarias 45} ción. Desde ese punto de vista, la ciudad neoliberal es un nicho de reproducción capitalista y, por ello, Viale expresa que:

En las ciudades no son los terratenientes sojeros, ni la megaminería, ni las petroleras, sino la especulación inmobiliaria la que expulsa y aglutina población, concentra riquezas, produce desplazamientos de personas, se apropia de lo público, provoca daños ambientales y desafía a la naturaleza, todo esto en un marco de degradación social e institucional... Las tierras, los inmuebles del Estado y los espacios verdes son convertidos por la especulación inmobiliaria en la pata urbana de la desposesión. (Viale, 2017, p. 16)

Inspirado en la geografía crítica de Harvey, pero desarrollando instrumentos teóricos para la ciudad, Viale argumenta que los inmuebles urbanos equivalen a los commodities agrícolas y que esas propiedades han dejado de ser un bien de uso para convertirse en un bien de cambio. No obstante, nosotros vamos a afirmar que en los negocios impulsados en las ciudades latinoamericanas también están los terratenientes y productores sojeros, no actuando en persona o estableciendo corporaciones extractivistas in situ, sino como inversores de parte de su renta en bienes inmuebles urbanos. Aunque algunos economistas sostengan que la correlación entre renta total agraria y crecimiento de la industria de la construcción no ha sido demostrada en la 
Argentina, numerosos estudios urbanos avalan esa hipótesis con elocuencia (Barenboim, 2010; Elinbaum y Barenboim, 2018; Rausch et al., 2019).

En el caso del área central de la Argentina, los mercados inmobiliarios locales contribuyen al crecimiento vertical de las ciudades e incrementan los precios de las unidades de vivienda, expulsando a las clases medias a vivir en bajas densidades en las periferias urbanas dispersas. En lo que respecta a las clases bajas, mientras aumentan los metros cuadrados construidos, crece la cantidad de personas que vive en asentamientos informales y carentes de los servicios más básicos. De ese modo, casi todo lo construido por el sector privado es asequible a un número cada vez más reducido de personas, mientras el sector público parece desentenderse de la construcción de viviendas de interés social o terceriza esa función a través de subsidios que no alcanzan a resolver el creciente déficit habitacional.

Según Martínez Toro (2018), en ese archipiélago metropolitano existen conjuntos arquitectónicos aislados y discontinuos donde domina una policentralidad segmentada socio-espacialmente y definida por la consolidación de un sector inmobiliario que ha sido cooptado por el capital financiero. Sus agentes privados impulsan y producen una oferta residencial fraccionada en desarrollos celulares con una localización determinada por las franjas de precios finales de los artefactos residenciales. Además, mientras las autopistas habilitan suelo para el desarrollo de barrios cerrados periféricos, los terrenos centrales degradados - entre los cuales se hallan los predios ferroviarios en desuso- son incorporados a procesos de renovación urbana donde se construyen torres de viviendas de alto estándar y oficinas corporativas.

Si bien ahora asistimos a una fase de recesión en la Argentina, el crecimiento de la actividad económica desde el año 2003 había sido sostenido por las exportaciones debidas al ventajoso precio internacional de los commodities. Eso generó rentas extraordinarias en el sector agrícola, creándose también grupos de inversores inmobiliarios en torno a la figura del fideicomiso. Es decir, un contrato por el cual una o más personas transmiten bienes, dinero o derechos de su propiedad a otra, para que esta los administre o invierta. En este sistema de administración y construcción, ninguna de las partes es propietaria del edificio objeto del fideicomiso, por cuanto los bienes afectados no corren riesgos y el patrimonio involucrado no puede ser alcanzado por acreedores, ni afectado por la quiebra de alguno de los inversores. Además, esa modalidad aplicada a las operaciones inmobiliarias estuvo alentada porque

la falta de confianza en el sistema financiero, generada por la crisis de comienzos de siglo, y las bajas tasas de interés determinaron la inversión de estos beneficios extraordinarios en la industria de la territarios 45 229 
construcción [...] De este modo, se pasó de la especulación financiera de los años ochenta y noventa a la inmobiliaria. Los bienes inmuebles comenzaron a comportarse como un activo financiero produciendo, por un lado, grandes ganancias y, por otro, un incremento más que significativo en el precio de los inmuebles. (Barenboim, 2010 , p. 25)

En el panorama exportador posterior a la crisis del 2001, las ciudades del área central tuvieron "ventajas comparativas". En lo que respecta al modelo de crecimiento en la ciudad de Santa Fe y alrededores, hay consenso en atribuirlo a la expansión de la industria de la construcción por desconfianza en el sistema financiero y para resguardar los capitales y las operaciones inmobiliarias invirtiendo "en ladrillos”. En el GSF, en los últimos trece años, se construyó el $40 \%$ de las torres erigidas en las tres décadas precedentes y en el período 2003-2010 se edificó el 32\% de los bloques del área central (Rausch et al., 2019). En simultáneo, hubo un crecimiento extensivo, fragmentario y difuso hacia el norte y en zonas costeras (Mai \& Neffen, 2011), ver figura 5.

La ciudad de Rosario, también en la Provincia de Santa Fe, emergió como uno de los sitios más favorecidos por el nuevo escenario macroeconómico debido a la disponibilidad de un conjunto de puertos exportadores y de un complejo aceitero en una región muy productiva. Asimismo, el desmantelamiento de las viejas instalaciones ferroportuarias sobre la ribera del

Figura 5. Construcción de torres en las inmediaciones de la ex estación Belgrano

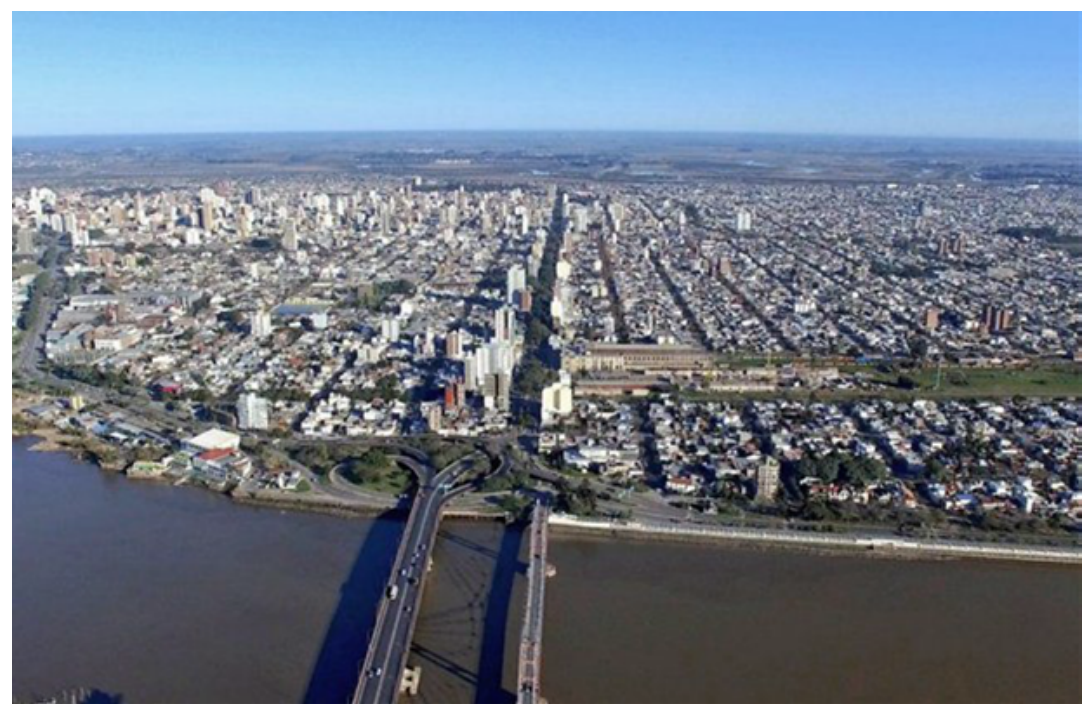

Fuente: tomado del diario Uno Santa Fe (“El viernes vencen las restricciones...”, 2021). 
río Paraná había permitido incorporar parte de esas tierras fiscales a un sistema de parques (Barenboim, 2014), pero la recuperación de esos predios tendría otra faz en los albores del nuevo milenio con un proceso de construcción intensivo y privatizado.

El Proyecto Puerto Norte en esa ciudad es un claro ejemplo de esas actuaciones. La urbanización del predio provocó que el valor del suelo se triplicara debido a la aplicación de la nueva normativa. Eso ha significado un gran beneficio para los desarrolladores a partir de los nuevos índices de edificación. Si bien el municipio ha capturado parte de ese incremento para construir viviendas sociales, lo hizo en otros sectores de la ciudad realizando obras de infraestructuras aledañas al predio. Así, las compensaciones por mayor aprovechamiento urbanístico suelen tener un impacto distributivo ambiguo o regresivo porque benefician a los emprendimientos o a los sectores colindantes a estos (Peinado et al., 2018). Esas propuestas a menudo se materializan a través de edificios emblemáticos y pueden concebirse como estrategias de marketing urbano, ahondando la propensión latinoamericana hacia ciudades poco inclusivas que completan los vacíos con operaciones de elite (Etulain, 2008).

Según cifras analizadas por Barenboim (2019), los permisos de obra se incrementaron en Rosario de 350.685 $\mathrm{m}^{2}$ a $1.792 .834 \mathrm{~m}^{2}$ entre 2003 y 2007 , mostrando el área central un acelerado proceso de sustitución. Se afirma que ello ha traído una batería de conflictos urbanos como: incremento del parque automotor, contaminación ambiental, extracción del arbolado, problemas con el transporte público, desplazamiento de familias jóvenes a la periferia, colapso de las infraestructuras y modificación de la fisonomía de los barrios; conflictos que motivaron la propuesta de un nuevo código urbano. También sostiene Barenboim (2019) que el crecimiento vertical en el centro está acompañado de un aumento de viviendas ociosas y señala que no hay paridad entre las propiedades ofrecidas y las buscadas en cuanto a la cantidad de ambientes disponibles, predominando una sobre oferta de unidades pequeñas.

Ahora bien, como ya ha sido señalado, las mismas ciudades que exhiben sitios plagados de torres, muestran desarrollos de bajísima densidad en otros lugares. Esto se debe a un mecanismo de auto regulación que es de naturaleza económica ya que, además de las condiciones de producción, intervienen las de consumo del bien y estas no son uniformes en todo el espacio urbano (Jaramillo, 1994). En este caso, el excedente tiene dos componentes: la ganancia que remunera al inversionista y la renta percibida por el propietario del suelo. La competencia entre constructores hace que estos no puedan esperar mayor ganancia que la ofrecida en el mercado, entonces la diferencia por localización es absorbida por el propietario de la tierra. Como a mayor número de niveles las territarios 45 231 
técnicas constructivas aumentan sus costos, la razón de la construcción en altura radica en que es posible percibir una renta por el terreno.

Mientras las ciudades se densifican, por otro carril transitan las estadísticas dramáticas del déficit habitacional, lo que conduce a preguntarnos ¿para quiénes se construye con tanta avidez? Según Coraggio y Muñoz (2018) la industria de la construcción está sustituyendo a la manufacturera, pero genera menor cantidad de puestos de trabajo que esta. Por otra parte, el capital financiero ha sido puesto al servicio de sufragar los altos costos de la construcción, que también son debidos a los dilatados tiempos de ejecución de los bienes inmuebles. Entonces, el afán especulativo queda vinculado a entidades bancarias, desarrolladores, fondos de inversión y pequeños ahorristas que invierten su ganancia o su renta en unidades de vivienda. Se crea así una reproducción de lo urbano que impulsa a los promotores inmobiliarios a elevar sus beneficios con usos de alta rentabilidad y compradores solventes.

Si bien, desde hace tiempo, y a causa de la transición del régimen de acumulación Fordista - o del desarrollismo en América Latina - hacia modalidades de especialización flexible, ha habido un paulatino aumento de la desregulación, de la globalización y del dominio del capital financiero, Ciccolella (2017) sosterritarias 45 tiene que, por primera vez en la historia del desarrollo urbano, el crecimiento de la ciudad se ha independizado del crecimiento demográfico. Para este autor, las ciudades están siendo convertidas en un gran negocio inmobiliario, materializado en edificios con unidades de lujo muchas veces en estado ocioso, mientras la planificación estatal no cuestiona, o incluso auspicia, la captación privada de las plusvalías generadas.

En la Ciudad Autónoma de Buenos Aires, según estadísticas analizadas por Ciccolella (2017), en los últimos años había alrededor de 150.000 hogares sin una vivienda digna, mientras otras 350.000 unidades persistían desocupadas. Asimismo, la media del metro cuadrado de suelo urbano costaba 500 dólares en el año 2000 y una década después rondaba los 1.700. Por otra parte, en el espacio periurbano - donde los precios de los bienes inmuebles son más accesiblespredominan los desarrollos deficientes por su baja densidad de ocupación, con escasa dotación de infraestructuras y carentes de servicios públicos. De modo que, la extensión en horizontal en búsqueda de terrenos baratos y bajo formas difusas está alentando, además, el uso del automóvil particular que propicia un tipo de movilidad insostenible. En consecuencia, ese modelo de crecimiento no solo es injusto y excluyente en términos habitacionales, también desafía las posibilidades del Estado de ofrecer servicios públicos de calidad. 


\section{Reflexiones finales}

En este artículo se ha cuestionado la existencia de commodities rurales y commodities urbanos para evidenciar, en cambio, sus interrelaciones y las dinámicas multiescalares que impregnan los territorios y las ciudades. Aunque actualmente se ha estabilizado el auge inicial, algunas aglomeraciones latinoamericanas y argentinas están siendo convertidas en receptoras de inversiones extranjeras en infraestructuras y, también, de las rentas extraordinarias generadas en el sector agrícola. Esas dinámicas profundizan las desigualdades socio-espaciales en los procesos de urbanización, alentando la construcción o renovación de infraestructuras de transporte, la privatización de bienes comunes de origen ferroviario y la expansión de la construcción como formas de absorber los excedentes del capitalismo en la ciudad neoliberal.

Si bien nuestro trabajo de investigación sobre renta total agraria y especulación inmobiliaria en el caso de Santa Fe está en una etapa preliminar, hemos avanzado sobre la situación problemática, la construcción del objeto y las hipótesis que han sido expuestas en este artículo. Nuestra principal inquietud académica se centra ahora en abrir una discusión sobre el destino de los predios ferroviarios centrales, que los operadores inmobiliarios anhelan y que son apetecidos para crear oportunidades de negocio. Como ha sido expuesto, las cadenas agrícolas y sus rentas estimulan la mercantilización del suelo urbano de un modo indirecto, que hemos intentado visibilizar. Aquí las infraestructuras ferroviarias - nuevas y obsoletas- están en disputa, y la industria de la construcción podría impulsar su consumo de formas que amenazan colonizar la política local y los bienes comunes que son estratégicos para encarar problemas de movilidad urbana, en parte, creados por el propio modelo de crecimiento.

Sostenemos que bordar los fenómenos suramericanos en su densidad socio espacial podría contribuir a explicar las dinámicas urbanas contemporáneas, su vínculo con las estrategias geopolíticas que incitan nuevos planes regionales y nacionales de transporte y su alianza con los sectores inmobiliarios locales. Ello permitiría arrojar luz sobre los desafíos teóricos y políticos que enfrenta la ciudad neoliberal en nuestra región. Se trata, entonces, de reconocer en la escala local urbana las singularidades de una dinámica macroeconómica ligada a un orden multiescalar de actores y factores, para así reflexionar sobre dimensiones alternativas de la selectividad del capital como productor de ciudades fragmentadas y excluyentes. 


\section{Referencias}

Aceval, A., \& Álvarez, Á. (2018, 19 de octubre). Disputas en el territorio ribereño de Santa Fe: Estudio del conflicto territorial por la infraestructura en la Vuelta del Paraguayo. I Jornadas Platenses de Geografía, La Plata, Argentina.

Arrighi, G. (1999). El largo siglo XX. Dinero y poder en los origenes de nuestra época. Akal.

Barenboim, C. (2010). Dinámica inmobiliaria en la ciudad de Rosario (Período 1998-2009). Proyección, (8), 21-44. https://bdigital.uncu.edu.ar/objetos_digitales/11478/03-proyeccion8barenboin.pdf

Barenboim, C. (2019). Normativa urbana y sus efectos en la constructibilidad: la implementación del nuevo Código Urbano en la ciudad de Rosario. Agenda de reflexión en arquitectura, diseño y urbanismo, AREA, 25(2), 1-18. https://publicacionescientificas. fadu.uba.ar/index.php/area/article/ view/367

Barenboin, C. (2014, agosto-diciembre). Evolución histórica de la costa central y su vinculación con el gran proyecto urbano de Puerto Norte en la ciudad de Rosario, Argentina. Revista iberoamericana de estudios municipales, RIEM, 2(10), 61-81. http://hdl.handle.net/11336/30879

territarias 45

Barzola, E., \& Baroni, P. (2018). El acercamiento de China a América del Sur.
Profundización del neoextractivismo e incremento de conflictos y resistencias socioambientales. Colombia Internacional, (93), 119-145. https://doi. org/10.7440/colombiaint93.2018.05 Bolinaga L., \& Slipak, A. (2015). El Consenso de Beijing y la reprimarización productiva de América Latina: el caso argentino. Revista Problemas del Desarrollo, 183(46), 33-58. https://doi. org/10.1016/j.rpd.2015.10.003

Brenner, N. (2003). La formación de la ciudad global y el re-escalamiento del espacio del Estado en la Europa occidental post-fordista. Eure, 29(86), 5-35. https://doi.org/10.4067/ S0250-71612003008600001

CAF otorga U\$S326 millones para la recuperación del Belgrano Cargas. (2010, 6 de octubre). Énfasis logística. https:// logisticasud.enfasis.com/historico/ caf-ortorga-us326-millones-la-recuperacion-del-belgrano-cargas/

Castaños, M. (2018, 12 de agosto). Ya es ley: expropian terrenos para la concreción de una nueva red ferroviaria. $L a$ Capital. https://www.lacapital.com. ar/la-region/ya-es-ley-expropian-terrenos-la-concrecion-una-nueva-redferroviaria-n 1656915.html

Ciccolella, P. (2017). Especulación inmobiliaria y déficit habitacional: diagnóstico crítico y sistémico de la problemática. En Vásquez Duplat A. M. (Comp.), Extractivismo urbano: debates para una construcción colectiva de las ciudades (pp. 49-57). Fundación 
Rosa Luxenburgo; Centro de Estudios y Acción por la Igualdad (Ceapi); El Colectivo.

Circunvalar Santa Fe: se confirmó el financiamiento de una empresa china. (2019, 20 de junio). El Litoral. https://www.ellitoral.com/index. php/id_um/199971-circunvalarsanta-fe-se-confirmo-el-financiamiento-de-una-empresa-china-las-obrascomenzarian-en-diciembre-y-se-finalizarian-en-2021-area-metropolitana. html

Coraggio, J. L., \& Muñoz, R. (Eds.). (2018). Economía de las ciudades de América Latina hoy (Vol. I: Enfoques multidisciplinarios). Universidad Nacional de General Sarmiento, UNGS.

El viernes vencen las restricciones: ¿qué pasará con las clases, el comercio y los bares? (2021, 09 de junio). Uno Santa Fe. https://www.unosantafe. com.ar/santa-fe/el-viernes-vencen-lasrestricciones-que-pasara-las-clases-elcomercio-y-los-bares-n2666598.html

Elinbaum, P., \& Barenboim, C. (2018). Efectos metropolitanos de una política de vivienda mixta. El caso del ProCreAr. Cuadernos de Vivienda y Urbanismo, 11(21), 1-20. http://hdl. handle.net/10554/37370

Etulain, J. C. (2008). La gestión urbanística mixta de intervención en vacíos urbanos de ciudades centrales. Caracterización, análisis e instrumentos. Estudios del Hábitat, (10), 45-57. http://sedici. unlp.edu.ar/handle/10915/32802
Fernández, V. R. (2016). Desde el laboratorio neo-desarrollista a la resurgencia neoliberal. Una revisión creativa del "doble movimiento" polanyiano en América Latina. Estado y Politicas Públicas 7, 21-47. http://hdl.handle. net/11336/55276

Gómez Lende, S. (2015). El modelo sojero en la Argentina (1996-2014): un caso de acumulación por desposesión. MERCATOR, 14(3), 7-25. http://hdl. handle.net/11336/10188

Harvey, D. (2004). El nuevo imperialismo. Akal.

Harvey, D. (2014). Diecisiete contradicciones y el fin del capitalismo. IAEN.

Hidalgo, R., Camus, P., Paulsen, A., Olea, J., \& Voltaire, A. (2016). Extractivismo inmobiliario, expoliación de los bienes comunes y esquilmación del medio natural. El borde costero en la macrozona central de Chile en las postrimerías del neoliberalismo. Innsbrucker Geographische Studien, Band 40, 251-270.

Jaramillo, S. (1994). Hacia una teoría de la renta del suelo urbano. Uniandes; Instituto Geográfico Agustín Codazzi, IGAC.

Katz, C. (2015, abril-junio). ¿Qué es el neodesarrollismo? Una visión crítica. Argentina y Brasil. Serv. Soc. Soc., (122), 224-249. https://doi. org/10.1590/0101-6628.021

Madrigal Tascón, L. (1988). Régimen jurídico del espacio ferroviario. En $\mathrm{Se}^{-}$ minario sobre Ferrocarril, Urbanismo 
$y$ Territorio (pp. 215-235). Fundación de los Ferrocarriles Españoles.

Mai, A, \& Neffen, G. (2011, 11 de septiembre). En la ciudad, hay un $30 \%$ más de departamentos que hace diez años. $E l$ Litoral. https://www.ellitoral.com/ index.php/diarios/2011/09/11/metropolitanas/AREA-02.html

Martínez Toro, P. (2018). Mercado inmobiliario y la producción del archipiélago metropolitano. La metropolización de Cali. Bitácora Urbano Territorial, 28(1), 9-24. https://doi. org/10.15446/bitacora.v28n1.40237

Merino, G. E., \& Adriani, H. L. (2019, julio-diciembre). Proyectos de integración, capitalismo global y "Plan Belgrano" en Argentina. Estudios Socioterritoriales, 26, 1-20. https://doi. org/10.37838/unicen/est.26-037

Nación quiere financiar el Circunvalar Ferroviario con la venta de los terrenos. (2018, 27 de julio). Aire de Santa Fe. https://www.airedesantafe.com. ar/nacion-quiere-financiar-el-circunvalar-ferroviario-la-venta-los-terrenos-n75396

Nuevo desarrollo urbanístico: se firmó el convenio entre AABE y la municipalidad de Santa Fe para urbanizar 24 hectáreas de la ciudad. (2018, 03 de diciembre). Prensa del Estado argentino. https://www.argentina.gob.ar/ noticias/nuevo-desarrollo-urbanistico-se-firmo-el-convenio-entre-aabey-la-municipalidad-de-santa-fe
Palmieri, P., \& Noguera, D. (2015, 3 al 5 de septiembre). Tierra y renta agraria en la Argentina: una aproximación empirica para el período 2002-2013. VIII Jornadas de Economía Crítica. Córdoba, Argentina.

Peinado, G., Barenboim, C., Nicastro, M., \& Lagarrigue, P. (2018). Recuperación de plusvalías urbanas y sus impactos distributivos. Las compensaciones por mayor aprovechamiento urbanístico a raíz de convenios urbanísticos en la ciudad de Rosario, Argentina. Sociedad y Economía, (35), 50-77. https:// doi.org/10.25100/sye.v0i35.7295.

Pereira, C. (2020, 07 de julio). En la continuidad del Plan Maestro de la Belgrano se juega la Santa Fe que queremos. El Litoral. https://www.ellitoral. com/index.php/id_um/251326-enla-continuidad-del-plan-maestro-dela-belgrano-se-juega-la-santa-fe-quequeremos-por-carlos-pereira-opinion. html

Pérez, C. (2010). Technological revolutions and techno-economic paradigms. Cambridge Journal of Economics, 34(1), 185-202. https:// doi.org/10.1093/cje/bep051

Rascovan, A. (2016). La infraestructura y la integración regional en América del Sur. Una visión geopolítica de los proyectos ferroviarios en el marco de IIRSA-COSIPLAN. Relaciones Internacionales, 25(51), 59-80. http://hdl. handle.net/11336/44070 
Rausch, G., Martínez, I., Nardeli, M., \& Szupiany, E. (2019). Concentración/ dispersión en Santa Fe, Argentina: problemáticas e interrogantes sobre los procesos urbanos contemporáneos en una ciudad media de América Latina. Cuadernos de Geografía, 28(1), 6688. https://doi.org/10.15446/rcdg. v28n 1.68757

Renovaron más de $200 \mathrm{~km}$ de vías del Belgrano Cargas. (2017, 20 de septiembre). Prensa del Estado argentino. https://www.argentina.gob.ar/noticias/renovaron-mas-de-200-km-devias-del-belgrano-cargas

Rivera, M., Lujano, J., \& García, J. (2018). El quinto Kondratiev global. Bajo desempeño económico, inestabilidad y monopolización en la era digital [Archivo pdf]. http://www.economia.unam. $\mathrm{mx}$ /academia/inae/images/ProgramasyLecturas/lecturas/inae_iv/riverama2018.pdf

Rodrigue, J. -P. (2013). The Geography of Transport Sistems. Routledge.

Schweitzer, M. (2014, enero-junio). Políticas ferroviarias en la argentina. Planes y proyectos en la primera década del siglo XXI. Transporte y Territorio, (10), 13-32. https://doi.org/10.34096/ rtt.i10.501
Sobre el posible Desarrollo Urbanístico detrás de la Estación Belgrano. (2018, 02 de diciembre). \#Encuentro. https:// encuentrosantafe.com.ar/sobre-el-posible-desarrollo-urbanistico-detras-dela-estacion-belgrano-2/

Swyngedouw, E. (2004). Globalisation or "Glocalisation"? Networks, Territories and Rescaling. Cambridge Review of International Affairs, 17(1), 25-48.https://doi. org/10.1080/0955757042000203632

Terrenos de Candioti Sur: ¿Quién se queda con la torta? (2018, 26 de julio). Aire de Santa Fe. https://www.airedesantafe. com.ar/terrenos-candioti-sur-quiense-queda-la-torta-n75399

Theodore, N., Peck, J., \& Brenner, N. (2009, marzo). Urbanismo neoliberal: la ciudad y el imperio de los mercados. Temas Sociales, (66), 1-12. http://barcelonacomuns.pbworks.com/w/file/ fetch/64059073/2009_Urbanismo_ neoliberal_brenner-peck-.pdf

Viale, E. (2017). El extractivismo urbano. En Vásquez Duplat A. M. (Comp.), Extractivismo urbano: debates para una construcción colectiva de las ciudades (pp. 15-20). Fundación Rosa Luxenburgo; Centro de Estudios y Acción por la Igualdad (Ceapi); El Colectivo. 